\title{
Aquilo que a amamentação retira e o desmame restaura: relatos maternos sobre tensionamentos e materiais de comunicação e informação em saúde
}

\author{
What the breastfeeding removes and the weaning restores: maternal \\ narratives about tensions and health discourses and educational materials

\section{Lo que la lactancia materna arrebata y el destete restaura: relatos maternos acerca de tensiones y discursos de salud y materiales educativos}

Irene Rocha Kalil ${ }^{1, a}$

irene.kalil@icict.fiocruz.br | https://orcid.org/0000-0001-5232-0573

Adriana Cavalcanti de Aguiar ${ }^{1, b}$

adriana.aguiar@icict.fiocruz.br | http://orcid.org/0000-0002-7182-3114

${ }^{1}$ Fundação Oswaldo Cruz, Instituto de Informação e Comunicação Científica e Tecnológica em Saúde, Laboratório de Comunicação e Saúde. Rio de Janeiro, RJ, Brasil.

Doutorado em Ciências pela Fundação Oswaldo Cruz.

${ }^{\mathrm{b}}$ Doutorado em Educação pela Harvard University.

\section{RESUMO}

Os discursos pró-aleitamento materno contemporâneos reforçam certos sentidos acerca da amamentação, ao mesmo tempo que silenciam outros, afeitos à relação da mulher com seu corpo, sua sexualidade e seu trabalho, bem como o processo de desmame. Neste artigo, buscamos, à luz da análise de discursos de inspiração foucaultiana, da psicanálise e de estudos feministas, dar visibilidade aos sentidos atribuídos pelas mulheres à experiência de amamentação, em toda sua complexidade, incluindo o desmame. Entrevistamos 11 mulheres que haviam amamentado e vivenciado o último desmame havia, no máximo, dois anos. Encontramos similaridades entre relatos maternos e discursos oficiais, mas identificamos também tensionamentos, perdas e ressignificações que a mulher experimenta no período de amamentação. As falas sobre o desmame (e mudanças decorrentes dele) indicam que este se encontra associado ao sentido de liberdade, de restauração de aspectos da identidade feminina que haviam sido tomados da mulher durante a gravidez e o período de amamentação.

Palavras-chave: Aleitamento materno; Desmame; Estudos de gênero; Saúde pública; Comunicação em saúde.

\begin{abstract}
Contemporary pro-breastfeeding speeches reinforce certain meanings about breastfeeding, while silencing others, such as the woman's relationship with her body, sexuality and work, as well as the weaning process. In this article, based on the discourse analysis by Foucault, on psychoanalysis and on feminist studies, we seek to reveal the meanings attribute by women who breastfeed to their experience while breastfeeding in all its complexity, including weaning. We interviewed 11 women who had breastfed and waned their babies up to two years ago. We found similarities between maternal narratives and official speeches, but we also identified tensions, losses and resignificances that women went through during breastfeeding. Their answers about weaning (and its consequences) indicate its association with the sense of freedom, and with the
\end{abstract}


restoration of aspects of the female identity that had been taken away from the woman during pregnancy and the breastfeeding period.

Keywords: Breastfeeding; Weaning; Gender studies; Public health; Health communication.

\section{RESUMEN}

Los discursos contemporáneos en favor de la lactancia refuerzan ciertos significados sobre esa experiencia, mientras silencian otros, como la relación de la mujer con su cuerpo, sexualidad y trabajo, así como el proceso de destete. En este artículo buscamos, a la luz del análisis de discursos inspirado por Foucault, del psicoanálisis y de estudios feministas, dar visibilidade a los significados que las mujeres atribuyen a la experiencia de la lactancia, en toda su complejidad, incluido el destete. Entrevistamos 11 mujeres que habían amamantado y experimentado el último destete en el plazo máximo de dos años atrás. Encontramos similitudes entre los informes maternos y los discursos oficiales, pero también identificamos tensiones, pérdidas y nuevas significaciones que las mujeres experimentan durante la lactancia. Las respuestas sobre el destete (y los cambios que se derivan de él) demuestran que éste está asociado a la sensación de libertad, de restaurar aspectos de la identidad femenina que habían sido arrebatados de la mujer durante el embarazo y en el periodo de la lactancia.

Palabras clave: Lactancia; Destete; Estudios de género; Salud pública; Comunicación sobre salud.

Este artigo compõe o dossiê Feminismos: perspectivas em comunicação e informação em saúde, parte 2.

Contribuição dos autores:

Concepção e desenho do estudo: Irene Rocha Kalil.

Aquisição, análise ou interpretação dos dados: Irene Rocha Kalil e Adriana Cavalcanti de Aguiar.

Redação do manuscrito: Irene Rocha Kalil e Adriana Cavalcanti de Aguiar.

Revisão crítica do conteúdo intelectual: Adriana Cavalcanti de Aguiar e Irene Rocha Kalil.

Declaração de conflito de interesses: não há.

Fontes de financiamento: não houve.

Considerações éticas: CAAE:80761917.6.0000.5269. Número do Parecer: 3.900.919.

Agradecimentos/Contribuições adicionais: não há.

Histórico do artigo: submetido: 10 mar. 2021 | aceito: 27 jul. 2021 | publicado: 31 ago. 2021.

Apresentação anterior: não há.

Licença CC BY-NC atribuição não comercial. Com essa licença é permitido acessar, baixar (download), copiar, imprimir, compartilhar, reutilizar e distribuir os artigos, desde que para uso não comercial e com a citação da fonte, conferindo os devidos créditos de autoria e menção à Reciis. Nesses casos, nenhuma permissão é necessária por parte dos autores ou dos editores. 


\section{INTRODUÇÃO}

Este artigo apresenta resultados inéditos do projeto de pesquisa Percepções maternas sobre a experiência de amamentação e desmame, aprovado pelo Comitê de Ética em Pesquisa em Seres Humanos do Instituto Nacional de Saúde da Mulher, da Criança e do Adolescente Fernandes Figueira (IFF/Fiocruz), que buscou conhecer, descrever e dar visibilidade às percepções de mães sobre a amamentação e o desmame, e suas implicações para elas, seus filhos e famílias. Tal projeto insere-se na sequência de trabalho anterior sobre análise dos discursos oficiais para promover e orientar o aleitamento materno (AM) no Brasil, que apontou a inexistência ou escassez de uma abordagem mais complexa da amamentação, que inclua o desmame, nos materiais oficiais de promoção do AM (KALIL, 2016).

Em geral, tais discursos têm sua ênfase numa relação predominantemente instrumental: a mulher produz e fornece ao/a seu/sua filho/a o 'melhor alimento', o leite materno, seguro e completo, com valor nutricional e imunológico inestimável para a saúde da criança. Não mencionam aspectos da subjetividade da mulher que amamenta, nem sua inserção no mundo do trabalho, e secundarizam dificuldades, colocando, de modo simplório, no desejo da mulher a condição de continuar amamentando, mesmo com o fim da licença maternidade, "com frases generalizantes como 'toda mulher é capaz de amamentar" (KALIL; AGUIAR, 2020, p. 47).

Entre os achados mais significativos do trabalho de análise dos materiais oficiais sobre AM, encontra-se o silenciamento de determinados sentidos relativos à prática, tais como: as perspectivas da mulher acerca do processo; a relação do pai da criança com a amamentação; e o desmame, aqui compreendido como interrupção completa da amamentação e transição necessária na relação entre bebê, mãe e mundo social.

Nesse sentido, as questões identificadas como silenciamentos foram abordadas no projeto de pesquisa anteriormente citado, por meio de entrevistas semiestruturadas realizadas com mulheres que haviam amamentado e concluído o processo de amamentação, gerando dados sobre os sentidos da amamentação e desmame produzidos na vivência dessas mães, também influenciados pelos discursos oficiais, midiáticos, entre outros, pois entendemos, como Araújo (2006), que "nenhum indivíduo vive isolado e que os sentidos individuais são socialmente constituídos" (p. 5).

Historicamente, os discursos pró-AM do século XX concorreram para o acirramento da divisão sexual do trabalho, conceito que, na acepção de Hirata e Kergoat (2007), emerge da percepção da carga de trabalho, realizada de forma gratuita e 'invisível' socialmente, exercida pelas mulheres, não em seu próprio benefício, mas para outros. O trabalho doméstico seria desenvolvido, segundo as autoras, "sempre em nome da natureza, do amor e do dever materno", e se contrapunha, em certa medida, ao trabalho profissional, assalariado, "pensado até então apenas em torno do trabalho produtivo e da figura do trabalhador masculino, qualificado, branco" (p. 597-598). As mulheres acabaram, portanto, acumulando a participação nas esferas reprodutiva e produtiva (HIRATA; KERGOAT, 2007), na dinâmica conhecida como dupla jornada de trabalho.

Da mesma forma, esses discursos oficiais atuais pouco problematizam as interações e os impactos sociais decorrentes da amamentação, como o trabalho feminino - seja doméstico ou no mercado de trabalho formal -, e a participação do pai ou companheiro(a) na amamentação e no cuidado com o(a) filho(a) (por exemplo, como emerge no conceito da maternagem, prática que pode ser exercida pela mãe, mas também pelo outro que compartilha o cuidado).

Nem mesmo a Cartilha para a mãe trabalhadora que amamenta (BRASIL, 2015), publicada pelo Ministério da Saúde (MS) em 2010 e atualizada em 2015, aborda as dificuldades enfrentadas pela mulher que trabalha fora e amamenta, não dedicando uma linha sequer para tratar da possibilidade do desmame no retorno da mulher ao trabalho após o nascimento do bebê ou do impacto emocional dessa situação de 
separação. Por fim, os discursos oficiais predominantemente individualizam a prática da amamentação, atribuindo à mulher a maior parte da responsabilidade, como idealiza o material: "É possível manter seu filho com leite materno mesmo depois de voltar a trabalhar fora? Temos certeza de que sim!” (BRASIL, 2015, p. 26), como se fosse possível escapar à lógica das relações capital X trabalho no atual contexto brasileiro.

Com o desmame sendo ainda pouquíssimo estudado e debatido no campo da saúde (para além da variante do desmame precoce), a terceira parte de nossas entrevistas foi totalmente dedicada a investigar a experiência desse que é um dos mais acintosos silenciamentos dos discursos pró-aleitamento materno (KALIL, 2016). Buscamos, a partir da perspectiva das mulheres participantes, detalhar aspectos como o motivo do desmame, duração, dificuldades enfrentadas, fontes de apoio durante o processo, auxílio de serviços/profissionais de saúde, bem como acesso a materiais educativos/informativos acerca do desmame. Mas, principalmente, interessava-nos saber quais os desdobramentos do desmame para a vida da mulher e da família como um todo.

Nossa escolha se deve, sobretudo, ao reconhecimento da importância do desmame no processo de subjetivação do indivíduo em formação, indicada pelo campo psicanalítico desde os escritos de Freud (1972). Como revelaram as falas das entrevistadas, o desmame também pode apresentar impactos físicos e emocionais, para a mãe, que abandona a relação de indissociação com o bebê, que se iniciara na gravidez. A despeito disso, ele permanece, ainda, em uma zona obscura, tanto no que tange à assistência especializada à saúde, quanto no que se refere aos discursos técnicos sobre a prática da amamentação.

Isso não chega a surpreender, se considerarmos que o MS brasileiro não costuma realizar pesquisas com mães que estão prestes a amamentar ou em fase de amamentação, como subsídio para elaboração ou avaliação dos materiais de promoção e orientação à prática da amamentação (KALIL, 2016). Raramente escutadas, as mulheres figuram menos como sujeitos e mais como instrumentos da política pública voltada à saúde infantil (KALIL; AGUIAR, 2016a).

Por isso mesmo, este artigo tem como objetivo dar visibilidade aos sentidos atribuídos pelas mulheres à experiência de amamentação, em toda sua complexidade, incluindo o desmame, tendo como horizonte teórico e metodológico a análise de discursos de inspiração foucaultiana, a psicanálise e as discussões fomentadas por estudos feministas. Algumas premissas que informam nossa discussão são: a idealização da maternidade nas representações discursivas hegemônicas - neste caso específico, no discurso oficial do Ministério da Saúde; os relatos de mulheres sobre suas experiências de amamentação e, sobretudo, de desmame como uma oportunidade na qual os discursos tensionam os modelos preconizados pelo discurso oficial, emergindo questões como direito ao próprio corpo, vida sexual e conjugal, vida profissional e a relação de tudo isso com a saúde física e emocional da mulher que opta por ser mãe e amamentar seu bebê; e que o trabalho no capitalismo está impregnado pela busca de obtenção do lucro, desconsiderando aspectos (inter)subjetivos dos trabalhadores e trabalhadoras, conforme expresso na longa luta por direitos reprodutivos e cuidado com a prole.

\section{REFERENCIAL TEÓRICO-METODOLÓGICO}

A cientista social Lucila Scavone, autora de diversos trabalhos que, ainda na década de 1980, trouxeram à luz a abordagem da maternidade sob a ótica socioantropológica e feminista, defende a existência de um fenômeno moderno que o sociólogo Anthony Giddens (1993) chamou de "invenção da maternidade", por meio da qual, em muitas camadas nas sociedades modernas, assiste-se ao "papel proeminente da mãe no cuidado inicial do filho" (p. 146). Tal modelo de maternidade se constituiria, segundo Scavone (2004), por uma associação da maternidade com a feminilidade, atrelando a mulher ao papel supostamente natural de mãe, "atribuindo-lhe todos os deveres e as obrigações na criação dos(as) filhos(as) e limitando a função social feminina à realização da maternidade” (p. 173). 
Em sua obra Dar a vida e cuidar da vida, de 2004, Scavone reúne textos previamente publicados, com pesquisas teóricas ou empíricas realizadas por ela sobre o que nomeou de "problemática sociológica das mulheres, especificamente no campo da saúde" (SCAVONE, 2004, p. 9). No livro, a autora estabelece ou consolida reflexões que consideramos fundamentais sobre a relação do feminismo com direitos reprodutivos, políticas de saúde e de gênero, e dedica sua parte final ao tema da maternidade, sua historicidade, suas múltiplas faces, e suas ligações com saúde, família e relações de gênero. Neste sentido, ela afirma que a normatização do corpo e dos cuidados com a vida levou a uma responsabilização da mulher pela saúde da família, e destaca que ela é ainda mais notória "nos períodos da gravidez e da amamentação, nos quais o ‘corpo-a-corpo’ da mãe com a criança possibilita a fantasia de causa e efeito” (p. 135).

Também Dagmar Estermann Meyer (2003, 2005), em seu profícuo trabalho articulando educação, estudos de gênero e saúde coletiva, observou uma nova "politização da maternidade", por meio da qual o processo de "gerar e criar filhos 'equilibrados e saudáveis' passa a ser social e culturalmente definido, também, como um 'projeto' de vida, responsabilidade individual de cada mulher que se torna mãe, independentemente das condições sociais em que essa mulher vive” (MEYER, 2003, p. 37). Segundo a autora, tal politização "é incorporada e difundida pelas políticas de Estado, pelos manuais, revistas, jornais, televisão, cinema e publicidade. E o modelo da mãe cuidadosa - que cuida e se cuida - triunfa e, ao mesmo tempo, se democratiza" (MEYER, 2005, p. 82).

É nesse esteio, de autoras como Scavone e Meyer, que buscamos sustentar o olhar analítico sobre nossos objetos de pesquisa no contexto brasileiro. Entre as autoras estrangeiras, destacamos a filósofa feminista francesa Elisabeth Badinter (1985, 2011), com obras cruciais para a desnaturalização do fenômeno da maternidade no mundo contemporâneo, engendrado, ainda no século XVII, pelo "mito que continuará bem vivo duzentos anos mais tarde: o do instinto materno, ou do amor espontâneo de toda mãe pelo filho" (BADINTER, 1985, p. 145), estando o aleitamento materno no cerne dessa filosofia moderna de maternidade.

O modelo contemporâneo de maternidade prevê a responsabilização da mulher pelos potenciais riscos à saúde de sua prole, além da necessidade (crescente) de apoio profissional e conhecimentos especializados na criação e educação das crianças. Para tal ideologia, chamada de maternagem intensiva (HAYS, 1998) ou maternidade total (WOLF, 2007), caberia à 'boa mãe' minimizar a exposição dos filhos a riscos, a despeito dos custos de tais esforços para sua própria vida.

Compondo o roteiro dessa "maternidade total", a amamentação constituiria a 'medida da mãe' (WALL, 2001), indicando a adequação da conduta materna aos padrões socialmente valorizados. Badinter (2011) identifica como o AM se constituiu como imperativo, contribuindo para constranger o papel social da mulher e, frequentemente, gerando culpa e sensação de impotência em mães que não podem ou querem amamentar. Neste sentido, diversas autoras feministas que investigam a maternidade contemporânea questionam os discursos recentes pró-AM (KALIL; COSTA, 2013). No Brasil, o AM emerge como elemento das 'pedagogias de maternidade', com suas redes de disciplinamento e controle social, impactando a produção de identidades de gênero (MEYER, 2003).

Por considerarmos tal abordagem bastante esclarecedora, o olhar problematizador dos estudos feministas norteia a perspectiva teórico-metodológica adotada nesta pesquisa, aliado à Análise de Discursos (AD) de inspiração foucaultiana. Foucault (2013) provoca-nos ao questionar certas formulações ou "sínteses acabadas, esses agrupamentos que, na maioria das vezes, são aceitos antes de qualquer exame, esses laços cuja validade é reconhecida desde o início” (p. 26). Segundo esse autor, caberia ao analista de discursos desnaturalizar os objetos, os conceitos e os discursos sobre eles, "expulsando-os da sombra onde vicejam e arrancando-os de sua quase evidência” (FOUCAULT, 2013, p. 31). Também para Pinto (1999), trata-se de compreender o discurso para além de sua aparente neutralidade, mas como produto de suas condições sociais de produção (também nomeadas 'contextos') e como espaço de lutas pelo poder. 
Na mesma direção, Orlandi (1999) preconiza um "estado de reflexão" que evita a "ilusão de sermos conscientes de tudo", ensejando "uma relação menos ingênua com a linguagem" (p. 9). Como orientação analítica, Orlandi (2007) nos instiga a valorizar "a historicidade do texto, os processos de construção dos efeitos de sentidos" para identificar o silêncio, que não pode ser observado diretamente, mas se desvela indiretamente por meio de métodos, sempre discursivos, que são "históricos, críticos, desconstrutivistas" (p. 45).

A autora chama a atenção ainda para o papel da memória pensada em relação ao discurso, chamada de 'memória discursiva ou interdiscurso': "aquilo que fala antes, em outro lugar, independentemente. [...] O saber discursivo que torna possível todo dizer e que retorna sob a forma do pré-construído, o já dito que está na base do dizível" (ORLANDI, 1999, p. 31). Na constituição dos sentidos, esse "pré-construído" atuaria além dos próprios sujeitos físicos, compondo os regimes de verdade que estão na raiz desses discursos. Tais elementos da memória discursiva são compartilhados e correspondem a outros sujeitos/vozes que se fazem presentes nos discursos, ainda que aquele que fala não tenha consciência e/ou controle sobre eles.

Assim, partimos da premissa de que as mães entrevistadas produzem discursos (como efeitos de sentidos), de forma consciente, mas também inconsciente, com base em discursos que as precedem, como os discursos oficiais para promover e orientar o AM (no presente e também forjados ao longo dos últimos dois séculos). Reconhecemos que existe uma concorrência discursiva, ou seja, os discursos oficiais não ecoam sozinhos na sociedade. Entretanto, para fins da pesquisa em curso e deste artigo, nosso recorte são as aproximações e distanciamentos, as similaridades e os tensionamentos, ou, ainda, as continuidades e descontinuidades dos sentidos produzidos pelas mães entrevistadas, em suas experiências de amamentação e desmame, e os discursos oficiais, objeto de análise anterior (KALIL, 2016).

\section{COLETA DE DADOS}

Este artigo apresenta resultados da análise de onze entrevistas realizadas. Visando a minimizar o viés da memória, os critérios de seleção estabeleceram que, na ocasião da entrevista, as mães houvessem realizado o (mais recente) desmame há, no máximo, dois anos.

A seleção de participantes baseou-se na técnica de 'bola de neve', na qual uma participante indica outra participante em potencial, e, assim, sucessivamente. Tal escolha metodológica é vantajosa em pesquisas exploratórias, quando é difícil localizar possíveis participantes (pelos critérios estabelecidos) e, particularmente, quando a pergunta de pesquisa está relacionada a alguma temática potencialmente sensível (VINUTO, 2014), como entendemos ser o caso do AM. Entre as suas limitações, sobressai a possibilidade de, sendo a indicação de informantes feita pelos pesquisadores e pelos próprios informantes (amostragem de conveniência), enviesar os resultados, por exemplo, pela participação de indivíduos de um mesmo estrato socioeconômico e cultural, apresentando experiências e discursos semelhantes.

As participantes iniciais foram selecionadas entre contatos da primeira autora e algumas delas indicaram uma ou mais informantes. O primeiro contato com as potenciais participantes foi feito pelo aplicativo Whatsapp e, na sequência, as entrevistadas receberam por e-mail e responderam com sua anuência o Termo de Consentimento Livre e Esclarecido (TCLE), que apresentava a pesquisa e seus objetivos de forma genérica para evitar influenciar os depoimentos. As primeiras entrevistadas foram selecionadas entre mães conhecidas de creche, escola etc. Depois, esse universo se ampliou por meio da indicação das próprias entrevistadas ou de conhecidas de pessoas amigas.

Isso constituiu, como antecipado, um perfil de mulheres bastante homogêneo do ponto de vista sociocultural, com alto grau de escolaridade, renda própria e amplo acesso a fontes de informação (oficiais ou não), as quais as entrevistadas buscam ativamente. Pode-se considerar que mulheres com esse perfil seriam mais preparadas que a média para nomear suas experiências, negociarem necessidades familiares 
no ambiente de trabalho, bem como para resistirem a modelos de maternidade que desconsiderem suas vivências e sentidos atribuídos.

As entrevistas foram realizadas entre julho de 2019 e abril de 2020, tendo cinco delas ocorrido presencialmente, nos locais de trabalho das entrevistadas ou em cafés próximos às suas residências, e seis, de forma remota por telechamada ou videochamada (duas delas por motivo de as entrevistadas residirem em outro estado que não o das pesquisadoras e as outras quatro em razão do isolamento decorrente da pandemia de Sars-Cov-2). A primeira autora realizou as entrevistas, seguindo roteiro semiestruturado constituído por 27 perguntas distribuídas em três partes: 1) Perfil socioeconômico e familiar da entrevistada; 2) Experiência do processo de amamentação; e 3) Experiência do processo de desmame. As entrevistas foram gravadas em arquivo de áudio e, após a gravação, foram transcritas integralmente. Na apresentação dos resultados, as entrevistadas receberam nomes fictícios que elas mesmas escolheram (ou delegaram a escolha às pesquisadoras), preservando, dessa forma, seu anonimato.

\section{RESULTADOS E DISCUSSÃO}

Com relação ao perfil socioeconômico e familiar das entrevistadas, na época das entrevistas, sua idade variava entre 33 e 42 anos (idade média de 39 anos). Elas informaram escolaridade que variava de superior incompleto (uma pessoa) até doutorado completo, sendo que seis afirmaram possuir pós-graduação lato ou stricto sensu (residência, especialização, mestrado, doutorado). Com relação à área de formação, sete das entrevistadas possuíam graduação na área de saúde (fisioterapia, enfermagem, medicina, psicologia e nutrição). Apenas uma entrevistada não exercia atividade remunerada na época da entrevista e todas afirmaram trabalhar fora de casa (inclusive a que estava sem remuneração). Nove entrevistadas declararam renda mensal maior que cinco salários mínimos.

No que se refere ao estado civil, seis estavam casadas, enquanto cinco afirmaram possuir estatuto de união estável. Cinco entrevistadas tinham apenas um filho; outras cinco tinham dois filhos; e uma entrevistada tinha três filhos, somando um total de 18 crianças. A média de filhos era de, aproximadamente, 1,64 filho por mulher. Das 18 crianças, 14 (quase 80\% delas) eram menores de cinco anos, ou seja, podiam ser consideradas crianças pequenas. Todas as 18 crianças foram amamentadas, sendo que duas ainda se encontravam em fase de amamentação. $O$ tempo de amamentação variou de cinco a 50 meses (até o momento das entrevistas), sendo a duração média de 19,4 meses (1 ano e 7 meses). Tais dados confirmam a homogeneidade da amostra, que se concentrou nos estratos socioeconômicos mais elevados e com uma formação escolar que também propicia, ao menos em tese, o acesso a uma maior gama de informações advindas de fontes diversas - acerca da experiência de amamentação.

\section{Sentidos sobre corpo, sexualidade e trabalho durante a amamentação}

O corpo da mulher que amamenta é significado pelas entrevistadas como uma continuidade do corpo grávido, com mudanças que começam ainda na gravidez, o que chamamos aqui de 'corpo materno', que se constitui numa indissociação entre corpo da mãe e corpo do bebê. Enquanto algumas relataram uma relação tranquila e de aceitação com seu corpo, inclusive pelo emagrecimento pós-parto propiciado pela amamentação, outras falaram da frustração por não emagrecerem ao amamentar e uma relação 'não amigável' com o próprio corpo por não conseguirem voltar ao corpo prévio à gravidez.

Sobre o corpo materno, deve prevalecer o desejo de amamentar o bebê, sobrepondo-se o seio maternal ao seio erótico (fruto dos efeitos de uma sociedade tradicionalmente patricarcal, na qual o corpo da mulher é objetificado). A mulher se desapropria (em graus variados) do seu corpo em prol do bebê, tendo uma das mães afirmado que sentia, durante a amamentação, que uma parte do corpo era 'propriedade' da criança. 
Em paralelo ao sentimento de potência do corpo feminino, capaz de gerar e nutrir um outro ser, relatado por algumas mães, surge o sentido de invisibilidade da mulher ante a mãe. Uma delas afirmou que, no período em que amamentou, mal tinha tempo de se olhar, como que invisibilizando-se para si e para os outros:

A gente não consegue mais olhar pra gente, ninguém mais olha pra gente. Durante a gravidez, todo mundo só olha pra sua barriga, depois que o bebê nasce, todo mundo só olha pra criança e para o seu peito. (Diana)

Tal depoimento encontrou eco nas falas de outras mães:

\section{O foco era tão grande nela que eu nem prestava muita atenção em mim. (Helena)}

É aquela coisa que você realmente acaba deixando de existir, então você vai ficando lá em último plano. (Clara)

A relação conjugal, inclusive e principalmente no seu caráter íntimo, sexual, parece ser diretamente afetada pelas mudanças nos sentidos atribuídos ao corpo da mulher-mãe. A maioria das entrevistadas relatou afastamento de seus companheiros durante a amamentação. A citada indissociação entre corpo da mãe e corpo do bebê, para a maioria das mulheres entrevistadas, afetou a vida íntima conjugal. Algumas enxergam o afastamento do casal durante a amamentação como fato biológico, relacionado aos hormônios, e a essa necessidade instintiva da mãe zelar pela sobrevivência do bebê, o que pode constituir a base de uma relação simbiótica, proporcionando uma sensação de 'pertencer' mais ao bebê do que ao casal. Isso provocaria uma secundarização ou mesmo um negligenciamento da relação íntima pelas mulheres em razão de um 'afastamento' ou 'esfriamento' entre a mulher e seu companheiro, visto por algumas como 'se não existisse' ou como 'intruso' num cenário onde só caberiam dois, a mãe e seu bebê.

O seio, particularmente, veículo do leite materno e grande 'protagonista' da cena, é visto por algumas mulheres como um espaço sagrado, destinado apenas ao bebê e à amamentação, o que Sandre-Pereira (2003) já havia identificado como "tabu do seio materno" (p. 477), uma espécie de proibição que certos casais se impõem de tocar o seio que amamenta. O seio que pinga leite, relatado por várias entrevistadas, seria o responsável pelo ato, aparentemente comum entre mulheres que amamentam, de fazer sexo de sutiã. Se, antes da amamentação, o seio ocupava, provavelmente, um lugar de zona erógena, durante a experiência da lactação, o corpo materno, assexuado, sobrepõe-se ao corpo feminino, sexualizado.

Algumas falas demonstram isso, como de que a lactação "atrapalha muito porque, no início, só de encostar você tá toda molhada" (Diana), ou que a solução adotada foi "ter relação de sutiã o tempo inteiro porque, né, corre o risco de sujar o outro, de se sujar" (Diana), sendo o sutiã esse elemento de proteção do 'espaço sagrado', que é o seio que amamenta, pois, para muitas mulheres, como uma das mães entrevistadas, "dá muito nervoso assim de qualquer interação com o peito" (Violeta). Uma mãe também mencionou o seio como "área intocável", mas, segundo ela, não por ser sagrado, mas por ela apresentar uma 'hipersensibilidade' naquele local e temer sentir dor ao ser tocada durante o contato íntimo.

Algumas mulheres disseram acreditar que o afastamento do casal no período de amamentação se deve mais às dificuldades relacionadas ao que uma delas chamou de "conjunto da maternidade", como, por exemplo, o cansaço, potencializado por terem uma criança maior em casa, ou pelas poucas horas de sono. A única mãe entrevistada que alegou ter mantido a sua vida conjugal inalterada afirmou que tal fato se deve, precisamente, por não ter havido privação de sono, pois contou com a ajuda de técnica de enfermagem à 
noite, que ficava com as crianças entre as mamadas, além do fato de que as crianças tomavam fórmula e tinham de ser acordadas para mamar ou dormiriam a noite toda.

Uma das mães pontuou que a transformação da mulher em mãe e do homem em pai, com o nascimento do bebê, pesou na sua vida conjugal. Ela e o marido estavam muito voltados para o filho, o que teria provocado um distanciamento de ambos da relação conjugal. Ela relata, ainda, que seu marido agia, muitas vezes, como juiz do seu comportamento como mãe, criticando, por exemplo, o seu cansaço e irritação para amamentar quando chegava do trabalho.

Algumas mães também relataram terem ouvido brincadeiras dos maridos com relação ao fato de a criança já estar grandinha para continuar sendo amamentada. Embora viesse em tom de brincadeira, é provável que tais falas refletissem uma disputa e o desejo, ainda que inconsciente, de recuperar suas mulheres, com disponibilidade para eles e não apenas para os bebês. Uma delas lembrou a participação do marido no processo de desmame:

Ele cobrava também que tava na hora de tirar o peito. É verdade. Ele já cobrava há um tempo. (Mariana)

Tais achados vão ao encontro das teorias psicanalíticas. Desde as considerações de Freud na obra Três Ensaios sobre a Teoria da Sexualidade, de 1905, todo um campo de conhecimento passou a considerar a amamentação como estabelecimento de uma relação erógena entre mãe e filho(a), sendo o seio materno o primeiro "objeto sexual fora do corpo do próprio infante" (FREUD, 1972, p. 228) e a relação do bebê com a mãe que amamenta, o protótipo, para o indivíduo, de todas as suas relações amorosas posteriores. Segundo a psicanálise, durante a amamentação, na perspectiva da criança, haveria uma indissociação entre o corpo da mãe e o do bebê.

Mas, em contraposição a isso, o companheiro também foi relatado, por outra entrevistada, como elemento fundamental do sucesso das suas experiências de amamentação, oferecendo suporte e sendo compreensivo com as dificuldades pelas quais ela estava passando naquele processo.

Nos momentos em que eu me sentia mais louca, mais maluca, mais irritada, é muito positivo poder ter um companheiro que compreenda o processo, e que acolha, e que ajude. (Rochelle)

A relação das entrevistadas com o trabalho foi questionada às mães, visto que o discurso de viés moral situa a amamentação como função social da mulher (naturalmente responsável pelo cuidado do lar e da família), reforçando a divisão sexual do trabalho (KALIL; AGUIAR, 2016a). Fonte do precioso leite, o corpo feminino é tratado como instrumento para a garantia da saúde da criança em moldes apregoados pelos governos e por organizações internacionais (KALIL; AGUIAR, 2016a), a despeito do fato de que mulheres brasileiras de diversos estratos socioeconômicos integram, como componente imprescindível, tanto a esfera 'reprodutiva' (organizada em torno de atividades de gestar, parir, alimentar e cuidar das crianças e da família) quanto a produtiva, como parte da população economicamente ativa.

Segundo dados do último Censo Demográfico realizado pelo Instituto Brasileiro de Geografia e Estatística (IBGE, 2010), a força de trabalho feminina correspondia a 43,55\% do total, somando 39.870.376 pessoas, ou seja, é maciça a presença da mulher no mercado de trabalho formal e informal. Ainda segundo o IBGE, mulheres trabalhadoras são responsáveis pelo sustento exclusivo de 37,3\% das famílias brasileiras, a maioria delas 'monoparentais', ou seja, compostas pela mãe e seus filhos (IBGE, 2010). E, em artigo de 2012, Brasileiro et al. afirmaram que "quase $25 \%$ da população economicamente ativa é constituída por mulheres com filhos menores de seis meses de idade" (BRASILEIRO; AMBROSANO; MARBA; POSSOBON, 2012, p. 
647). Os indicadores do trabalho precário indicam que as mulheres são, inclusive, "mais numerosas do que os homens tanto no trabalho informal quanto no trabalho em tempo parcial" (HIRATA, 2009, p. 26), sendo particularmente atingidas pela precarização social e do trabalho.

Ainda assim, a Cartilha... (BRASIL, 2015), único material oficial de promoção do aleitamento materno que tematiza a relação entre trabalho e amamentação, a tônica é de incentivar que a trabalhadora traga demandas da esfera reprodutiva (relacionadas à alimentação do bebê) para suas relações e ambiente de trabalho, devendo sensibilizar superiores hierárquicos e colegas sobre a importância da amamentação para a saúde da criança e para sua assiduidade ao serviço. Desse modo, a mensagem é que o papel de mãe se sobrepõe aos demais, inclusive ao de profissional (KALIL; AGUIAR, 2016a).

De fato, a maior parte das mães que entrevistamos relatou algum grau de dificuldade no retorno ao trabalho, incluindo pressão da empresa e de si mesma para retornar logo (caso de uma empresária); longos períodos sem amamentar, com os peitos cheios de leite; e a ocorrência de repetidas mastites (inflamação das mamas). Esse retorno ao antigo posto profissional após ser mãe (ou estar novamente com um bebê pequeno que ainda mama), comumente, veio acompanhado de conflitos, como o relatou uma das mães que, ao voltar da licença maternidade, "era como se eu não pertencesse mais aos lugares, né. E eu só queria pertencer a um lugar, que era a minha casa junto com meu filho".

Também sobressai nas falas das entrevistadas a possível queda de seu desempenho no trabalho por falta de disposição ou de concentração decorrentes das mamadas noturnas, de seu pensamento estar focado no filho (que pode estar querendo mamar), da dificuldade de cumprir horários rígidos, de atender às expectativas sociais (e às próprias) de retornar a seu patamar de desempenho anterior à gestação e parto e de se reconectar afetivamente com o trabalho, além de um sentimento de culpa com relação à empresa precisar de seu trabalho no período da 'licença'.

Enquanto a recomendação do MS é a de amamentar exclusivamente até os seis meses de vida da criança, a maioria das mulheres com emprego formal tem apenas quatro meses de licença maternidade. Entre os homens, somente uma minoria teve a licença paternidade aumentada para 20 dias, tendo predominado o tempo de apenas cinco dias de licença sem prejuízo do salário. De acordo com o observado por Kalil e Aguiar (2016a), "a política oficial não leva em consideração os 'custos' da amamentação. Não se discute o montante de recursos que, sobretudo o Estado, mas também as empresas despendem com as licenças ampliadas" (p. 14).

Como a nossa amostra foi composta por mulheres que compõem uma parcela economicamente privilegiada da população, a tensão entre trabalho e amamentação se mostrou menos dramática. Somente duas delas - uma que era sócia de empresa e uma que era profissional liberal - não tiveram uma licença maternidade formal e fizeram ajustes às suas rotinas de trabalho e cuidados com o bebê. A maioria (nove entrevistadas) teve acesso à licença maternidade ampliada, de seis meses, e atuava em empresas e instituições que ofereciam benefícios às mulheres em fase de amamentação. Todas elas relataram as facilidades que os ambientes de trabalho proporcionaram à continuidade da amamentação de seus bebês, ou seja, os benefícios da flexibilização do trabalho para continuidade da amamentação: licenças mais longas, turnos mais curtos até a criança amamentada completar um ano, sala de amamentação e/ou creche na instituição/empresa, redução no número de atendimentos em consultório.

Sem desconsiderar os sentimentos negativos que permeiam momentos de separação da mãe do seu bebê, aparece, na fala de algumas entrevistadas, um enunciado interessante: o trabalho como uma brecha de liberdade da mulher com relação à função materna. Isso está colocado no depoimento dessa mãe, que diz: 
Ao mesmo tempo, não sei, acho que também te liberta de certa forma. Voltar a trabalhar é você também não ficar o dia inteiro relacionada a isso [o cuidado com a cria]. (Estela)

Outra mãe afirmou que, embora se sentisse mal por estar cansada de amamentar, nunca pensou em parar de trabalhar para ficar cuidando dos filhos em tempo integral:

Eu me sentia mal por estar cansada de dar de mamar, mas também nunca pensei em parar de trabalhar, nunca achei que esse era o momento. Eu morreria se eu ficasse um ano em casa. No final de um ano eu estaria me jogando pela janela... (Violeta)

Mesmo a mãe que relatou sensação de inadequação por seu retorno imediato ao trabalho (após o fim da sua licença maternidade), afirmou que, com o passar do tempo, recuperou o sentimento de pertencimento àquele lugar, a partir da compreensão de que ela não era somente mãe, mas tinha outras identidades para além da maternidade, conciliando diferentes papéis. Essa relativa ambiguidade materna com relação à dedicação aos filhos lança luz sobre as diversas identidades assumidas pela mulher profissional que opta por ser mãe em nossos dias, uma mulher que deseja a maternidade sem abrir mão de outros sonhos e projetos de vida.

As mães entrevistadas integram um estrato da população feminina que, em geral, não significa o trabalho apenas como meio de complementar a renda familiar, ou mesmo sustentar a família. São mulheres altamente escolarizadas e contam com trabalho remunerado em suas áreas de escolha profissional, o que favorece algum nível de satisfação com o exercício do seu ofício.

Na verdade, é possível observar, sobre a mulher trabalhadora que se torna mãe, uma cobrança social irreal [exagerada?], que surte efeitos nas mulheres, para que elas voltem - e rapidamente - a serem o que eram antes da maternidade. É a tal "conta que não fecha", como bem definiu a psicanalista Vera Iaconelli (2019): "Sentem-se em falta com o trabalho/carreira, com a vida amorosa, com os cuidados com o corpo e, acima de tudo, com os filhos. A perspectiva é de que elas deveriam e poderiam estar $100 \%$ em cada uma dessas atividades" (p. 77).

E não podemos esquecer que, no Brasil, ainda são insuficientes as políticas públicas que possibilitem à mulher amamentar sem a obrigação de voltar ao trabalho com um bebê ainda mamando exclusivamente ou iniciando a introdução alimentar, viabilizando trabalhar num horário reduzido durante os primeiros anos do bebê, além de permitir ao homem (que é pai) participar ativamente dos cuidados com o bebê (KALIL; AGUIAR, 2016a).

\section{Desmame, a interdição da mãe em favor da mulher}

Em sua análise dos discursos para promover e orientar o AM, Kalil (2016) observou que o desmame sofre uma espécie de interdição, como aquela nomeada por Foucault (2000) de 'tabu do objeto', sendo, na maioria das vezes, o que não pode ser dito, ou o 'interdito’ nesses discursos. Eni Orlandi (2007), autora que se dedicou a compreender as formas do silêncio no discurso, aborda o silêncio e sua relevância para compreender o discurso como materialização da interface entre ideológico e linguístico. Interpretamos o desmame e outros silêncios nos materiais de promoção e orientação relacionados ao AM como exemplos do que ela chamou de 'silêncio constitutivo', no qual "se diz 'X' para não (deixar) dizer ' $Y$ ' (p. 73). Dessa forma, "se apagam os sentidos que se quer evitar, sentidos que poderiam instalar o trabalho significativo de uma 'outra' formação discursiva, uma 'outra' região de sentidos” (p. 73-74).

Como exemplo, podemos citar a própria Cartilha... (BRASIL, 2015), voltada para as mulheres trabalhadoras que se tornam mães e amamentam. O documento detém sua atenção nos aspectos objetivos do retorno da mulher às atividades profissionais após o nascimento do bebê (sensibilização de chefia e 
colegas no ambiente de trabalho, estocagem de leite materno e treinamento do cuidador substituto para fornecê-lo à criança). Por outro lado, praticamente não aciona os sentidos da amamentação como relação que se estabelece entre as subjetividades de mãe e bebê, que aparecem somente em um trecho, quando menciona "o contato físico, o carinho, o estímulo" (BRASIL, 2015, p. 3) que a mãe sonha em dar para a criança e que a amamentação lhe permitiria proporcionar.

Aspectos sociais mais amplos da vida da mulher-trabalhadora-mãe-que-amamenta ou 'sintomas' de origem emocional que possam acometer o bebê ou a mãe quando se aproxima o fim da licença maternidade e o momento da volta dessa mãe ao trabalho não são abordados no material (KALIL; AGUIAR, 2017). Omitindo possíveis dificuldades da mulher - e mesmo da criança - em manter a amamentação após a retomada da rotina profissional pela mãe, a Cartilha... (BRASIL, 2015) silencia a problemática do desmame.

Um dos poucos materiais que mencionam o desmame para além da introdução gradativa de outros alimentos na dieta do bebê ou do desmame precoce, considerado problema de saúde pública, o Guia alimentar para crianças brasileiras menores de 2 anos (BRASIL, 2019), material mais recente publicado pelo MS, inclui enunciados confusos e, em certa medida, contraditórios. Ao mesmo tempo em que busca declarar o protagonismo da mãe, com enunciados como "Sob a liderança da mãe, algumas decisões e limites ao acesso ao peito vão sendo gradativamente impostos à criança, até a suspensão completa da amamentação" (p. 46), em seguida afirma que "Em geral, o desmame não deve ser forçado. Deve ocorrer de forma natural após os 2 anos de idade" (p. 46).

No desmame 'natural', de acordo com o material, a criança fornece à mãe "sinais indicativos" tais como "menor interesse nas mamadas; aceitação de alimentos variados; segurança na relação com a mãe; aceitação de outras formas de consolo que não o peito" (p. 46), de que está pronta para o desmame. O mesmo documento admite a existência de situações em que haja "necessidade ou desejo de desmamar a criança antes de ela estar pronta” (p. 46), e, nesses casos, orienta sobre alguns cuidados necessários. Ele finaliza afirmando que: "Cabe apenas à mulher e à criança a decisão final de manter a amamentação até que ocorra o desmame naturalmente ou interrompê-la antes disso. Essa decisão deve ser respeitada e apoiada por todos" (BRASIL, 2019, p. 47).

Em nossa amostra, quando perguntadas sobre o motivo do desmame total, apenas uma das 11 mães relatou desinteresse da criança, já com dois anos de idade, para mamar, e que em um desmame anterior seu leite havia secado naturalmente. A maioria das entrevistadas afirmou que o desmame ocorreu por iniciativa delas, por motivos pessoais ou sociais diversos, como: estar grávida e sentir medo de não ter leite suficiente para duas crianças ou temer que a criança achasse que perdeu peito para a irmã mais nova; estar em busca de trabalho fixo e medo de, caso conseguisse, o bebê ainda estar mamando (o que ocasionaria fazer o desmame e a adaptação em creche de forma brusca); ter uma viagem de trabalho agendada em que teria de se afastar do bebê; ter cumprido a 'meta' de amamentar até dois anos de idade da criança; sentir o peso do constrangimento pelo preconceito social com a amamentação tardia (de bebês maiores); sentir incômodo com o fato de a criança querer arrancar sua roupa e mamar em público; não aguentar mais o desgaste das mamadas noturnas; não estar feliz amamentando, ter sentimentos ruins ao amamentar, como raiva e irritação, não querer mais deixar de fazer outras coisas para amamentar; sentir-se exaurida, com um esgotamento físico que beirava adoecimento; e vivenciar uma sensação de 'aprisionamento', de 'interferência na liberdade', impedida de fazer escolhas simples, como sair à noite ou beber o que tivesse vontade.

Quanto à duração do desmame, as entrevistadas relataram desde o leite ter secado naturalmente, ou o bebê ter recusado uma mamada e não ter mamado mais, sendo a duração mais comum aquela entre três e quinze dias. Duas mães experimentaram um desmame mais gradual, que durou de um a cinco meses para ser concluído. 
Com relação à participação de outras pessoas no processo de desmame, além da mãe e do bebê, em primeiro lugar veio o pai da criança/companheiro, que assumia o consolo durante as primeiras noites nas quais a criança era impedida de mamar; e, em alguns casos, a avó materna da criança participou tanto no desmame diurno quanto no noturno. Duas entrevistadas contrataram uma consultora de sono para ajudar o bebê a dormir melhor à noite, o que, segundo elas, acabou levando ao desmame noturno e, posteriormente, ao desmame total. Uma das mães afirmou que preferiu fazer o desmame sozinha, permanecendo com a criança todo tempo, mesmo durante as madrugadas. Ela afirmou que, para isso, evitava ficar de camisola e tomar banho com bebê, além de usar roupas que deixassem o seio menos acessível ao filho.

As entrevistadas não recorreram a serviços de saúde em busca de apoio ao processo de desmame, que foi realizado de forma intuitiva ou espelhando-se na sua própria experiência anterior (para quem já havia amamentado antes). Algumas ajudas vieram de fontes mais informais, como conversas com amigas que também eram profissionais da área da saúde, como uma enfermeira que atuava como consultora de amamentação, ou, ainda, de uma consultora de sono para o desmame noturno, o que foi considerado positivo porque 'empoderou o pai' e tranquilizou-os de que a criança não precisava mamar de madrugada.

Uma das mães afirma ter consultado a psicóloga da creche da criança para entender a parte afetiva do desmame, mas avalia não ter encontrado muito acolhimento, ficando sozinha nessa decisão; enquanto outra buscou auxílio no banco de leite humano do hospital onde trabalha, tendo sido atendida por duas médicas com opiniões e encaminhamentos muito distintos com relação ao seu desejo de desmamar. Essa mãe diz ter se identificado mais com a profissional que considerou o ônus que a amamentação estava gerando para ela e apoiou sua decisão.

Com relação à consulta a materiais informativos e educativos sobre o desmame, algumas entrevistadas afirmaram não terem buscado materiais específicos sobre o desmame, mas terem encontrado algo sobre o assunto quando buscaram informações sobre a amamentação em geral. Outras foram em busca de informações oficiais, como os manuais produzidos pela Organização Mundial de Saúde (OMS), pelo MS e pela Fiocruz, e de artigos científicos recentes sobre o assunto. Também houve menção a contato com informações oriundas de sites, blogs, perfis e/ou comunidades em redes sociais de mães, nas quais puderam ter contato com relatos de experiências de outras mulheres. O obstetra de uma das mães entrevistadas, que atendia tanto na rede privada quanto na rede pública de saúde, disponibilizou materiais do SUS à paciente, enquanto outras duas mães afirmaram ter tido contato com as temáticas do desmame abrupto e do desmame gentil, uma em um grupo na internet e outra por meio de uma palestra para gestantes no trabalho. A maioria lembrava de ter lido alguma coisa, mas não recordava a fonte. Uma delas, que é enfermeira em unidade materno-infantil, afirmou ter consultado o Guia... (BRASIL, 2019), considerando reconfortante fazer suas escolhas com respaldo técnico.

A maioria das entrevistadas considerou úteis as informações disponíveis em materiais oficiais e nos grupos que compartilhavam experiências maternas, ainda que, em alguns casos, tenha optado por fazer de forma diferente. Uma delas, que trabalha em hospital, disse não ter encontrado material sobre o desmame no banco de leite humano procurado, o que considerou uma deficiência na atenção às mulheres que passam pelo processo e estão em busca de orientação.

As dificuldades vivenciadas no processo de desmame foram, principalmente, de cunho emocional: dificuldade psicológica com a ruptura (uma espécie de 'desmame da mãe'); dificuldade emocional por achar que a criança estava 'perdendo algo' (chegada de uma irmã, troca de creche); hesitação sobre parar ou não de amamentar e culpa por achar que estava 'roubando' um momento tão prazeroso para a criança e achar-se 'egoísta' por não ser tão 'paciente' (“será que eu não poderia ter amamentado um pouco mais?”); pena da criança pela perda do peito e um impacto emocional porque havia um apego de ambas, mãe e filha, à amamentação (relatado por muitas mães que amamentaram por dois anos ou mais); sensação de perda 
do único momento a sós com a filha mais nova; e dificuldade de lidar com o choro da criança. Uma das mães afirmou não ter vivenciado dificuldades com o desmame porque o leite secou naturalmente; e outra disse que teve dificuldade relacionada ao fato de a criança despertar à noite após o desmame e passar horas acordada (porque não tinha mais o peito para ajudá-la a adormecer).

Em geral, as mães descreveram a experiência do desmame como 'mais tranquila' do que haviam imaginado, utilizando enunciados como: gradual, suave, sem sofrimento. As primeiras madrugadas foram relatadas como mais difíceis, em função do choro do bebê que ainda quer mamar, e algumas delas admitiram terem sentido um 'misto de sentimentos': se, por um lado, queriam cuidar de si e estavam felizes por desmamar, por outro, sentiam-se "carregadas de culpa".

Ao descreverem o que mudou nas suas vidas com o desmame, algumas entrevistadas mencionaram a perda da praticidade que a amamentação possibilitava e a saudade de colocar o bebê no colo e do olho no olho para amamentar, demonstrando o sentimento de perda dessa relação íntima entre mãe e bebê e desse lugar de 'aconchego' para ambos. Entre as mudanças positivas, elas citaram: não ter mais hora para chegar do trabalho porque já não tinha o compromisso da mamada da noite; melhora do sono do bebê e da família, o que acaba por beneficiar outros aspectos; mudança na relação com o bebê, que deixa de ser 'o bebê da mãe' para ser o 'bebê da família', incluindo mais o pai e irmãos nessa relação; melhora da qualidade do relacionamento da mãe com o bebê, agregando momentos de brincar, ler histórias e outras atividades; amadurecimento da criança e da própria mãe; melhora da qualidade da relação com marido (algumas mulheres relataram um aumento da libido, possibilitando a retomada de sua vida sexual); e uma maior inclusão do marido no cuidado com bebê, ocasionando melhora na dinâmica familiar.

Algo digno de nota é o fato de que quase todas relacionaram o desmame à recuperação de autonomia sobre seu corpo e suas escolhas. A recorrente menção às palavras liberdade, libertação ou leveza reitera um aspecto da amamentação como aprisionamento da mãe à criança, ou, como expressou uma das entrevistadas, "o fardo de ter um bebê só grudado em mim". Isso fica nítido no depoimento dessa mãe, que expressou, de maneira contundente, a complexidade de sentimentos e sentidos que cercam a experiência de amamentação e desmame para a mulher:

Liberdade... porque... volto a falar... todos os louros para a amamentação, mas eu acho que a gente fica muito aprisionada [...]. É uma prisão em todos os sentidos. É uma solitária, talvez (...). Você é privado das suas escolhas, dos seus desejos. (Diana)

No mesmo sentido, algumas delas mencionaram que, após o desmame, puderam ter mais tempo para olhar para si mesmas como mulheres, pessoas, para além de mães, voltando a ter vaidade, desejo sexual e a investir em aspectos da vida, como o profissional, que ficaram negligenciados durante a amamentação. Ou seja: o desmame teria restituído a elas alguns aspectos da sua vida que lhe haviam sido 'tomados' com a gravidez e a amamentação.

Se entendermos, como Orlandi (1999), que "todo o funcionamento da linguagem se assenta na tensão entre processos parafrásticos e processos polissêmicos" (p. 36), sendo a paráfrase entendida como o retorno ao sentido sedimentado e a polissemia, como um deslocamento de sentidos, podemos inferir que, ao serem provocadas a falar do desmame, as entrevistadas tiveram a oportunidade de ressignificar a experiência de amamentação, deslocando sentidos e, em alguma medida, transformando-os.

\section{CONCLUSÕES}

Apesar de recordações agradáveis da amamentação, nas narrativas das entrevistadas é notório o tensionamento, em menor ou maior grau, entre suas experiências reais de amamentação e aquilo que ocupa 
o foco nos materiais oficiais de promoção e orientação relacionados ao AM. Estes, em geral, agregam à amamentação somente os sentidos positivos (parte do ser mãe, ato de amor, saúde para o bebê e a mãe, praticidade e economia para a família, entre outros), mas parecem 'esquecer' de abordar - ou, como diria Orlandi (2007), silenciam - uma espécie de 'lado B’ da prática, que inclui dores físicas e emocionais para a mulher que amamenta, desgaste físico e sensação de improdutividade em outros âmbitos da vida.

Além do cansaço gerado pela amamentação, algumas mães relataram sensações de aprisionamento e solidão (relacionadas ao fato de serem as únicas a poderem dar de mamar) e também de serem privadas "das suas escolhas, dos seus desejos", como descrito por uma das mães entrevistadas, em função das necessidades do bebê. Como expresso, de maneira contundente, nas narrativas dessas mães, há uma complexidade de sentimentos e sentidos que cercam a experiência de amamentação e de desmame para a mulher, a qual entendemos não estar, ainda, devidamente investigada nem contemplada nos materiais de comunicação ou na atenção à saúde sexual e reprodutiva.

O desmame, por sua vez, foi abordado aqui de forma inédita na perspectiva dos estudos da comunicação e saúde no Brasil. Entendemos que convocar as mães a descreverem suas experiências de desmame possibilitou-lhes um espaço para falar do aprisionamento da mãe ao bebê/criança (sobretudo durante o período de amamentação, em especial de amamentação exclusiva), numa relação de indissociação física entre mãe e criança que circunscreve a mulher à condição materna.

A função de mãe é preconizada como devendo preponderar sobre os demais papéis assumidos pela mulher brasileira contemporânea, e o discurso que prevalece se exime de problematizar os anseios e as expectativas, a vida conjugal, a preservação da liberdade de fazer escolhas acerca do próprio corpo, as condições de trabalho, salário e progressão profissional ou as dificuldades cotidianas de mulheres que optam ou, na maioria dos casos, precisam adotar a 'dupla jornada de trabalho', ou seja, são mães e trabalhadoras. A mulher torna-se, ao longo das gerações, secundária em relação à criança e à função materna. A iniciativa da mulher de realizar o desmame indica que, ao menos para as mulheres profissionais que entrevistamos, seu desejo as move em outras direções que não apenas o exercício de uma maternidade totalizante.

Faz-se necessário ressaltar, como limitação deste estudo, as peculiaridades da nossa amostra. As experiências abordadas neste artigo foram narradas por mães com alto grau de escolaridade e (provavelmente em função disso) que nutriam consideráveis expectativas com relação ao exercício de outros papéis sociais, tão caros às lutas feministas. Para além da função materna, existem como sujeitos conscientes do próprio corpo, preocupadas com sua vaidade e sexualidade, e como profissionais em busca de realização no trabalho. Consideramos, portanto, desejável, uma investigação mais ampla, que inclua as experiências de mulheres dos demais estratos socioeconômicos e culturais, ampliando a compreensão da complexidade da experiência de amamentação e desmame nas vidas das mulheres, e levando em consideração suas particularidades.

\section{REFERÊNCIAS}

ARAÚJO, Inesita Soares de. Materiais educativos e produção dos sentidos na intervenção social. In: MONTEIRO, Simone; VARGAS, Eliane (Org.). Educação, comunicação e tecnologia educacional: interfaces com o campo da saúde. Rio de Janeiro: Editora Fiocruz, 2006. p. 49-69.

BADINTER, Elisabeth. O conflito: a mulher e a mãe. Rio de Janeiro: Record, 2011.

BADINTER, Elisabeth. Um amor conquistado: o mito do amor materno. Rio de Janeiro: Nova Fronteira, 1985.

BRASIL. Ministério da Saúde. Secretaria de Atenção à Saúde. Cartilha para a mãe trabalhadora que amamenta. 2. ed. Brasília, DF: O Ministério, 2015. Disponível em: https://bvsms.saude.gov.br/bvs/ publicacoes/cartilha_mulher trabalhadora_amamenta.pdf. Acesso em: 17 ago. 2021. 
BRASIL. Ministério da Saúde. Secretaria de Atenção Primária à Saúde. Guia alimentar para crianças brasileiras menores de 2 anos. Brasília, DF: O Ministério, 2019. Disponível em: https://www.svb.org.br/ images/guia da crianca 2019.pdf. Acesso em: 17 ago. 2021.

BRASILEIRO, Aline Alves; AMBROSANO, Gláucia Maria Bovi; MARBA, Sérgio Tadeu Martins; POSSOBON, Rosana de Fátima. A amamentação entre filhos de mulheres trabalhadoras. Revista de Saúde Pública, São Paulo, v. 46, n. 4, p. 642-648, 2012. DOI: https://doi.org/10.1590/S0034-89102012005000053. Disponível em: https://www.scielo.br/j/rsp/a/RfB39JhnYc4BJJ8yQvq6J6C/?lang=pt. Acesso em: 17 ago. 2021.

FOUCAULT, Michel. A arqueologia do saber. 8. ed. São Paulo: Forense Universitária, 2013.

FOUCAULT, Michel. A ordem do discurso. 6. ed. São Paulo: Loyola, 2000.

FREUD, Sigmund. As transformações da puberdade. In: FREUD, Sigmund. Edição Standard Brasileira das Obras Psicológicas Completas de Sigmund Freud. Rio de Janeiro: Imago, 1972. v. 7, p. 213-252.

GIDDENS, Anthony. Distúrbios pessoais, problemas sexuais. In: GIDDENS, Anthony. A transformação da intimidade: sexualidade, amor e erotismo nas sociedades modernas. São Paulo: Editora Unesp, 1993. p. 125148.

HAYS, Sharon. Contradições culturais da maternidade. Rio de Janeiro: Gryphus, 1998.

HIRATA, Helena. A precarização e a divisão internacional e sexual do trabalho. Sociologias, Porto Alegre, ano 11, n. 21, p. 24-41, jan.-jun. 2009. DOI: https://doi.org/10.1590/S1517-45222009000100003. Disponível em: https://www.scielo.br/j/soc/a/TFYst3YmzhMvgZxJpXC983R/?lang=pt. Acesso em: 17 ago. 2021.

HIRATA, Helena; KERGOAT, Danièle. Novas configurações da divisão sexual do trabalho. Cadernos de Pesquisa, São Paulo, v. 37, n. 132, p. 595-609, set.-dez. 2007. DOI: https://doi.org/10.1590/S010015742007000300005. Disponível em: https://www.scielo.br/j/cp/a/cCztcWVvvtWGDvFqRmdsBWQ/ abstract/?lang=pt. Acesso em: 17 ago. 2021.

IACONELLI, Vera. Criar filhos no século XXI. São Paulo: Contexto, 2019.

INSTITUTO BRASILEIRO DE GEOGRAFIA E ESTATÍSTICA (IBGE). Censo Demográfico 2010. Rio de Janeiro: IBGE, 2010. Disponível em: https://censo2010.ibge.gov.brl. Acesso em: 17 ago. 2016.

KALIL, Irene Rocha. De silêncio e som: a produção de sentidos nos discursos pró-aleitamento materno contemporâneos. Rio de Janeiro: Multifoco, 2016.

KALIL, Irene Rocha; AGUIAR, Adriana Cavalcanti de. Silêncios nos discursos pró-aleitamento materno: uma análise na perspectiva de gênero. Revista Estudos Feministas, Florianópolis, v. 25, n. 2, p. 637-660, 2017. DOI: https://doi.org/10.1590/1806-9584.2017v25n2p637. Disponível em: https://www.scielo.br/j/ref/a/ JfhzM9SXMSGKTD55WnTXwJy/abstract/?lang=pt. Acesso em: 17 ago. 2021.

KALIL, Irene Rocha; AGUIAR, Adriana Cavalcanti de. Narrativas sobre Amamentação e Desmame: entrelaçamentos de experiências, políticas públicas e saúde. Revista GEMInIS, São Carlos, v. 11, n. 3, p. 4569, set.-dez. 2020. Disponível em: https://www.revistageminis.ufscar.br/index.php/geminis/article/view/554 Acesso em: 17 ago. 2021.

KALIL, Irene Rocha; AGUIAR, Adriana Cavalcanti de. Protagonista da amamentação ou instrumento da política de saúde infantil?: a enunciação da mulher nos materiais oficiais de promoção e orientação ao aleitamento materno. Saúde e Sociedade, São Paulo, v. 25, n. 1, p. 31-42, 2016a. DOI: https://doi.org/10.1590/S010412902016139049. Disponível em: https://www.scielo.br/j/sausoc/a/pCvDDBKqSxMCKLm58n8S59C/ abstract/?lang=pt. Acesso em: 17 ago. 2021.

KALIL, Irene Rocha; AGUIAR, Adriana Cavalcanti de. Trabalho feminino, políticas familiares e discursos próaleitamento materno: avanços e desafios à equidade de gênero. Saúde em Debate, Rio de Janeiro, v. 40, n. 110, p. 208-223, jul-set 2016b. DOI: https://doi.org/10.1590/0103-1104201611016. Disponível em: https:// www.scielo.br/j/sdeb/a/FMZrcBYBdyBZSxbsvzKXQvS/abstract/?lang=pt. Acesso em: 17 ago. 2021.

KALIL Irene Rocha; COSTA, Maria Conceição da. Entre o direito, o dever e o risco: olhares de gênero sobre amamentação. PerCursos, Florianópolis, v. 14, n. 27, p. 07-32, jul.-dez. 2013. DOI: https://doi.org/10.59 65/1984724614272013007. Disponível em: https://www.revistas.udesc.br/index.php/percursos/article/ view/1984724614272013007. Acesso em: 17 ago. 2021. 
MEYER, Dagmar Estermann. Educação, saúde e modos de inscrever uma forma de maternidade nos corpos femininos. Movimento, Porto Alegre, v. 9, n. 3, p. 33-58, set.-dez. 2003. DOI: https://doi.org/10.22456/19828918.2817. Disponível em: https://seer.ufrgs.br/Movimento/article/view/2817. Acesso em: 17 ago. 2021.

MEYER, Dagmar Estermann. Uma politização contemporânea da maternidade: construindo um argumento. Gênero, Niterói, v. 6, n. 1, p. 81-104, 2005. Disponível em: https://periodicos.uff.br/revistagenero/article/ view/31010. Acesso em: 17 ago. 2021.

ORLANDI, Eni Puccinelli. Análise de discurso: princípios e procedimentos. Campinas: Pontes, 1999.

ORLANDI, Eni Puccinelli. As formas do silêncio: No movimento dos sentidos. Campinas: Unicamp, 2007.

PINTO, Milton José. Comunicação e discurso: Introdução à análise de discursos. São Paulo: Hacker, 1999.

SANDRE-PEREIRA, Gilza. Amamentação e sexualidade. Estudos Feministas, Florianópolis, v. 11, n. 2, p. 467-491, jul.-dez. 2003. DOI: https://doi.org/10.1590/S0104-026X2003000200007. Disponível em: https:// www.scielo.br/j/ref/a/dzPhnPy44THTBFdfKTc7kmR/?lang=pt. Acesso em: 17 ago. 2021.

SCAVONE, Lucila. Dar a vida e cuidar da vida: feminismo e ciências sociais. São Paulo: Editora Unesp, 2004.

VINUTO, Juliana. A amostragem em bola de neve na pesquisa qualitativa: um debate em aberto. Temáticas, Campinas, v. 22, n. 44, p. 203-220, 2014. DOI: https://doi.org/10.20396/tematicas.v22i44.10977. Disponível em: https://econtents.bc.unicamp.br/inpec/index.php/tematicas/article/view/10977. Acesso em: 17 ago. 2021.

WALL, Glenda. Moral constructions of motherhood in breastfeeding discourse. Gender \& Society, [s. I.], v. 15 , n. 4, p. 592-610, ago. 2001. DOI: https://doi.org/10.1177\%2F089124301015004006. Disponível em: https:// journals.sagepub.com/doi/10.1177/089124301015004006. Acesso em: 17 ago. 2021.

WOLF, Joan B. Is breast really best? Risk and total motherhood in the National Breastfeeding Awareness Campaign. Journal of Health Politics, Policy and Law, Durham, v. 32, n. 4, p. 595-636, 2007. DOI: https://doi.org/10.1215/03616878-2007-018. Disponível em: https://read.dukeupress.edu/jhppl/ article/32/4/595/93544/Is-Breast-Really-Best-Risk-and-Total-Motherhood-in. Acesso em: 17 ago. 2021. 